\title{
THE PROBLEM OF PROSOPAGNOSIA
}

\author{
E. S. BEYN AND G. R. KNYAZEVA \\ From the Institute of Neurology, U.S.S.R. Academy of Medical Sciences, Moscow
}

Among the great diversity of visual gnostic disorders there is one variety of particular interest: its basic symptom is the loss of the faculty to recognize human faces (prosopagnosia). Although the existence of such a disorder had been surmised by earlier authors (Charcot, 1887; Wilbrand, 1892; Darkshevich, 1909; Poppelreuter, 1917), it has only recently been accepted as a relatively specific form of visual agnosia (Bodamer, 1947). According to Hécaen and Ajuriaguerra (1956) and Hécaen, Angelergues, Bernhardt, and Chiarelli(1957), 25 cases were recorded between 1932 and 1950 and some 15 more descriptions of the syndrome have since appeared in the literature (cf. Davidenkov, 1956; Bornstein and Kidron, 1959).

In a recent paper, Chlenov and Beyn (1958) have attempted to analyse the disorder in three cases of varying degree of severity from the point of view of pathogenesis, symptoms, and localization. Although its complex nature was stressed, the authors argued that prosopagnosia differs both quantitatively and qualitatively from other forms of visual agnosia and may be regarded as a specific failure of the complex function upon which specific recognition of a given individual depends. It is to be regarded as a disorder of perception, except perhaps in the most severe cases in which visual memory is also affected.

In the present paper, a case of pronounced prosopagnosia with some involvement of visual memory is communicated.

\section{CASE REPORT}

Ch., aged 39, was admitted to the Institute of Neurology on 30 March 1959 with complaints of inability to recognize colours or faces, a defect of spatial orientation, right-sided visual field defect, impairment of memory, a feeling of tension in the left half of the body, mild headaches, and increased irritability.

The onset of the illness was said to have been quite sudden and to have followed a drinking bout one year before admission. At this time, the patient experienced severe headache and total blindness for four or five hours, after which vision was restored but acuity did not improve for three weeks. A stable residual right homonymous hemianopsia was in evidence. In October 1958 headache and loss of vision recurred, but this time the picture was more extensive, involving optic agnosia, disorder of spatial orientation, and mild amnesic aphasia.

At the time of the second attack of loss of vision, blood pressure was $110 / 75 \mathrm{~mm}$. $\mathrm{Hg}$. Blood and cerebrospinal fluid findings were normal. There was papilloedema of the left disc and the right showed some pallor. The veins were unevenly dilated. There was right-sided homonymous hemianopia with macular sparing, a left-sided upper quadrantic field defect, and left-sided hemihypaesthesia.

According to the medical history, blood pressure rose sometimes to $160 / 100$ or to $150 / 90 \mathrm{~mm}$. Hg.

The patient had been wounded in 1944 by a bullet penetrating the right brachial plexus. This led to a peripheral paresis of the right arm and an aneurysm of the subclavian artery and vein. The aneurysm was ligatured.

On admission, the patient's general state was satisfactory. Arterial pressure was $150 / 95$ to $120 / 70$ $\mathrm{mm}$. Hg. The left side of the heart was slightly dilated, the second sound on the aorta somewhat accentuated. An E.C.G. showed a flattening of the $R$ and $T$ waves, indicating some myocardial changes. Cerebrospinal fluid findings were normal.

The fundi appeared normal. The patient had a right homonymous hemianopia and left-sided superior quadrantic field defect (Fig. 1). His visual acuity was 1.0 and he had slight horizontal nystagmus. Also he had a residual peripheral paresis from the old brachial plexus wound with associated sensory changes. No general cerebral or meningeal symptoms were elicited.

A radiograph of the skull was normal.

ELECTRO-ENCEPHALOGRAPHIC EXAMINATION The alpha activity was not pronounced. The zonal distinctions proved to be obliterated. Irregular slow waves of varying

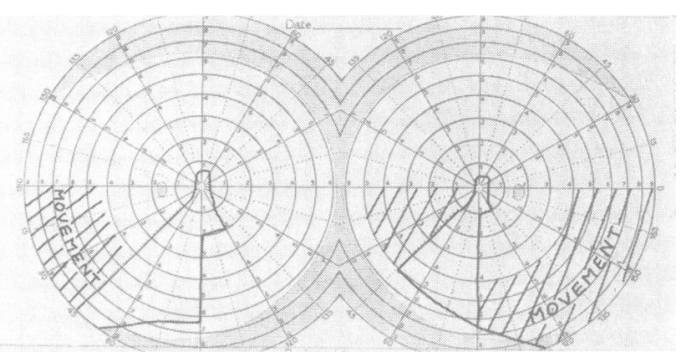

FIG. 1. Perimetric charts of visual fields. 
amplitude alternated with sharp waves and runs of low frequency beta rhythm. The disorganization was particularly evident in the cortical leads. Reactivity on photic stimulation was adequate. The picture was that of marked diffuse E.E.G. changes without focal features.

EXAMINATION OF COLOUR VISION This was carried out at the Scientific Research Laboratory of Colour Vision. The use of both spectral and pigment testing methods established an acquired pathological disturbance of colour vision (raised thresholds for discrimination of red, yellow, green, and blue).

Rapport was good and the patient had considerable insight into his disabilities. He was cooperative and well motivated throughout the investigation. He was discharged 40 days after admission but was readmitted six months and again five months later for follow-up study and rehabilitation.

To sum up the clinical features, bilateral field defects, visual agnosia, and a defect of spatial orientation of sudden onset in a man of 39 with an old right brachial plexus injury are consistent with disturbances of the cerebral circulation due to emboli in the posterior cerebral arteries. Probably there are bilateral foci of softening in the occipital lobes.

\section{PROSOPAGNOSIA AND RELATED DEFECTS}

PROSOPAGNOSIA The patient failed to recognize his relatives or physicians by sight and occasionally failed to recognize himself in the mirror. It was difficult for him to appreciate the sex and age of a person from his face but at the same time he acquired some facility in recognizing people by indirect means, e.g., by voice, stature, general appearance, spectacles, etc. He was unable to identify well-known historical or public figures from their portraits or to identify his wife and members of his family from photographs. Sometimes, however, a vague feeling of familiarity would attach to a figure which he was none the less unable to identify. The individual features of a face portrayed in a photograph, e.g., hair style, beard, could often be correctly reported and the patient could sometimes describe from memory the appearance of individuals whom he was unable to identify by sight. He was quite unable to judge emotional expression from photographs (physiognomic perception).

COLOUR AGNOSIA Colour perception was very disturbed. A careful study showed that the patient could in the main differentiate only brightness and saturation. Different hues of approximately equal saturation were readily confused. Classification of objects in terms of colour was gravely affected though classification in terms of shape remained intact. In general, blues and greens of low saturation were perceived as 'bright', dark browns, reds, and blues as 'black'. At the same time, the patient could specify the colours of common objects, e.g., coal, snow, from memory though he had difficulty in recalling a number of objects of a given colour when required to do so. He had no difficulty in enumerating objects in terms of categories other than that of colour. The patient tended to describe objects he saw as 'greyish' or 'pinkish' and his experiences of colour seemed both vague and liable to fluctuate. On one occasion he said: 'There seems to be a single colour, but suddenly when I look from here the colour changes ... Isn't it miraculous?'

VISUAL OBJECT-AGNOSIA Disorders of objectrecognition were much less in evidence and only observed sporadically. For example, he once reported difficulty in distinguishing a small cube from a lump of sugar. He could in general recognize coloured pictures of objects, but made some errors with contour figures or more schematic drawings. Tachistoscopic perception of objects was virtually impossible though letters and words exposed for comparably brief intervals were much more readily appreciated. There was some difficulty in perceiving complex pictures (simultaneous agnosia), in part due to the disability in recognizing faces and colours. The patient stated that his 'idea' of an object frequently failed to coincide with what he 'saw' and he was often unable to recognize after a short interval an object which had featured in an earlier experiment.

VISUAL MEMORY The defects described above did not appear to be wholly due to a disorder of perception. The patient reported difficulty in reproducing in memory the streets of his native town or in describing well-known buildings there or in Moscow. His description of certain objects from visual memory, e.g., different fruits, was also poor though their nature and uses were correctly stated. The concrete, particular and individual attributes of common visual objects appeared to have become somewhat schematic and de-differentiated.

COPYING AND DRAWING An experiment was carried out to compare the patient's capacity to draw objects from memory with his ability to copy the same objects. It was found that the patient could, in general, copy drawings of objects well though he was quite unable to draw identical objects from memory. It was noteworthy that his copies were often quite detailed and precise yet he was quite incapable of identifying the object copied. An example of this discrepancy between copying and drawing from 


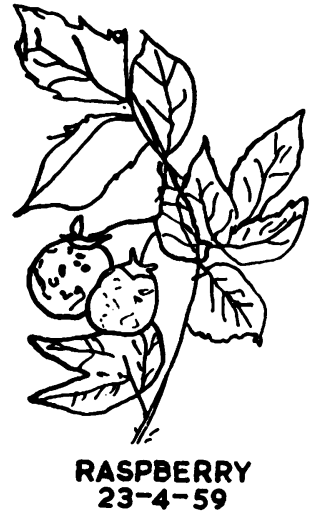

\section{RASPBERRY 23-4-59}

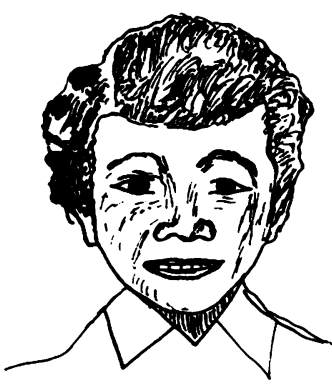

"MIKE"

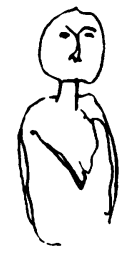

"MIKE" 27-5-59

FIG. 2. (Left) Copy of a drawing (without recognition). (Right) Attempt to reproduce the same drawing from immediate memory.

memory is shown in Fig. 2. If the model was removed, the patient was quite unable to continue with his copy from immediate memory.

In general, it was found that if the patient could 'imagine', i.e., 'represent', the appearance of an object he was much more likely to recognize it. Thus he recognized only three of 16 objects which he was unable to 'imagine', but 13 out of 16 objects which he could represent to himself by means of visual imagery. At the same time, he was commonly unable subsequently to 'imagine' even objects which he had correctly identified. Visual learning thus appeared to be appreciably impaired.

Although the relations between visual recognition and recall are undeniably complex, there appears to be some connexion in this case between the patient's conception of an object and his ability to recognize it.

OTHER FUNCTIONS Apart from slight nominal aphasia at the onset of the illness, no disturbances

of speech function were in evidence. Calculation was preserved. He did not suffer from apraxia and constructional performance was adequate. Perception of visual form and localization of objects in space was correct in spite of poor spatial orientation. Analysis and synthesis of visual patterns was adequate.

In the sphere of memory, recall of a list of 10 words was correct after four presentations but given a series of 10 pictures only three or four could be remembered. The patient's general memory was fair but he was apt to confuse the order of events in his personal history.

Intellectual function in general was intact. This was indicated by the good standard of critical thought and by his highly effective attitude to his rehabilitation course. His verbal reasoning, comprehension of proverbs, etc., appeared to be at an extremely good level.

\section{COURSE OF THE DISORDER}

During the patient's first stay at the Institute of Neurology (40 days) no essential change in the state of gnostic functions was recorded. Six months later, following the patient's second admission to the Institute, a certain improvement in the recognition of objects, in perception of pictures, and in visual memory could be noted. The patient at this time showed considerably greater emotional stability and appeared better adapted to his disability. For example, he made greater use of compensatory methods, e.g., comparing the colour of a given object with that of an object such as his own fountain pen, the colour of which was well known to him. He also made better use of incidental features in recognizing persons and places.

At his third admission five months later, there was very slight improvement in recognition of pictures and of facial expression. This was much assisted by systematic practice given in the recognition of facial expression from photographs and in making the patient aware of specific facial features for purposes of individual recognition. In this connexion, much use was made of the patient's intact capacity for verbal analysis and of his well-preserved ability to copy. An example of his copying and drawing from memory at this stage are shown in Fig. 3. It was thought that some improvement in recognition of faces under normal circumstances was brought about by this procedure.

\section{DISCUSSION}

We may first ask whether prosopagnosia can occur as an independent gnostic disability. The general 


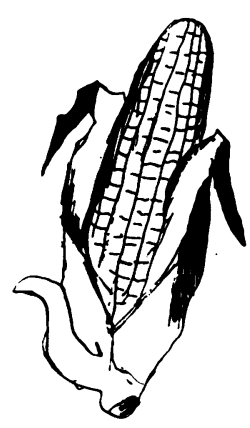

MAIZE

25-10-60

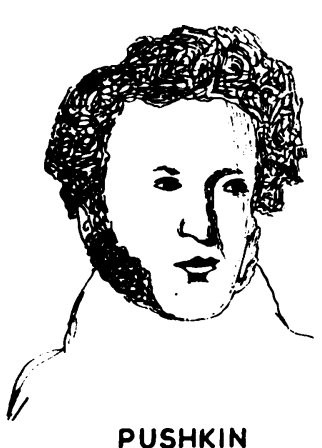

PUSHKIN
$28-9-60$

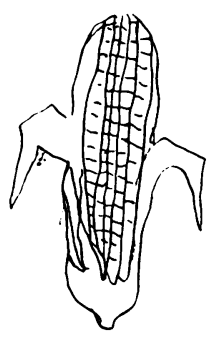

MAIZE 25-10-60

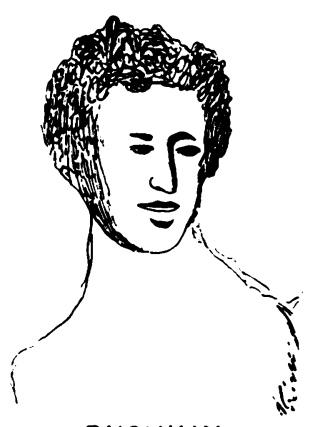

PUSHKIN 28-9-60
FIG. 3. (Left) Copy of a drawing (with recognition). (Right) Reproduction from immediate memory.

view appears to be that it very seldom presents in isolated form and almost always forms part of a more widespread disorder. Its combination with colour agnosia, spatial disorders, simultanagnosie, and visual object-agnosia has been frequently described and has led many to conclude that no very specific localization is possible. Indeed most of the patients described in the literature have had extensive right-sided or (more commonly) bilateral lesions.

On the basis of Pavlov's views, Davidenkov (1956) has stressed that 'the various manifestations of visual agnosia must be explained not by differences in localization but by differences in the form and degree of the inhibitory state of the visual cortex'. At the same time, such a view does not preclude a qualitative difference (arising from the peculiar character of the process of recognizing faces) as well as a quantitative difference (determined by the severity of the disorders) between prosopagnosia and other forms of higher visual disability.

Prosopagnosia has been explained by Bay (1952, 1953) and others in terms of visual field defect complicated by dementia. Although field defects have obvious importance, it is difficult to see how they can account for the highly specific nature of the disorder. Further, appreciable intellectual loss is by no means always present, as in our present case and in those of Pallis (1955) and Bornstein and Kidron (1959).

The point of view of Bodamer (1947) seems to us more acceptable. This author placed emphasis on the fact that the patient with prosopagnosia is typically able to distinguish the individual elements of a human face but cannot appreciate its unique character. Nor can he discriminate facial expression (cf. Chlenov and Beyn, 1958). Thus the phenomenon is evidently related to simultanagnosie but would none the less appear a special variant of this disorder.

The combination of prosopagnosia with a defect of visual imagination shown by our patient is reminiscent of the cases reported by Charcot (1887), Wilbrand (1892), and Hoff and Pötzl (1937). Our case has also a good deal in common with that reported more recently by Bornstein and Kidron (1959), though in this instance the disorder was less stable, and with one of the cases described by Chlenov and Beyn (1958). The condition may also be said to be reminiscent of what Lissauer (1890) long ago termed 'apperceptive agnosia' in so far as the patient is able to recognize objects as such but is unable to discriminate their unique and specific properties.

It is evident that prosopagnosia can vary in degree from complete loss of power to recognize faces even in their most generalized aspects (age, sex, etc.) to episodic failure to perceive the specific properties or expression of a given face. Our own patient clearly showed a severe degree of the disorder, which extended to other complex visual displays, e.g., pictures, topography. Further, the disorder was evidently not restricted to perception but involved also the conceptual sphere (visual memory). None the less, both intellect and personality were essentially intact.

The basic defect in the present case consisted in the fact that the patient was unable to identify familiar faces, rooms, or buildings. Spatial perception as such was not disturbed and there was no constructional disability. The patient could even distinguish between different types of buildings shown in pictures, e.g., a dwelling-house and a theatre, but was unable to recognize actual buildings or places which had previously been familiar to him, e.g., Sverdlov Square or the Bolshoi theatre in Moscow. In his attempted recognition of objects he tended to base identification on individual attributes or details much in the way that he 
recognized a particular person by his voice rather than by his face. Thus the defect of visual recognition may be ascribed to a failure to react to the combination of those specific features or properties of an object which endows it with uniqueness.

As in other cases of prosopagnosia, the disorder in this case was restricted to visual recognition. Identification of individuals by voice was fully intact and was indeed employed as a basic method of compensation. At the same time, the disorder shown in visual perception also affected visual memory. As has been said, the patient could imagine a street in its generic aspects but was unable to reproduce a specific street long familiar to him. His visual conceptions had also become less individual and more schematic. Involvement of the sphere of visual memory in this case testifies perhaps to the depth and severity of the cortical lesion.

A word is in place regarding the methods of re-education which were attempted. In the first place, an attempt was made to help the patient to compensate for his disability by making greater use of features other than the specific properties of a face, e.g., voice and general appearance. This, however, led to no improvement in the visual disability as such and only after prolonged practice had been given in the analysis of pictures and photographs, as well as real faces, was some improvement shown in physiognomic recognition. It was also thought that this procedure led to some improvement in the patient's capacity for visual refresentation. It might be suggested that the possibilities open to re-education in cases of higher visual disability should be further explored.

In conclusion, the variety of gnostic disorder presented in this case is of special interest in that it throws light on the mechanism and not merely the classification of visual agnosia. Agnosia may represent not merely a generic failure of object recognition (visual object-agnosia) but may also reflect specific incapacity to react to the unique characteristics of particular objects (faces, portraits, buildings, places). Generic recognition may thus be intact but individual recognition grossly impaired. Prosopagnosia reflects a failure in recognition at its most specific and highly individual level.

\section{SUMMARY}

A case of severe prosopagnosia (defect in physiognomic recognition) is reported in a case of bilateral occipital lobe lesion due to cerebrovascular disease. This defect was associated with some degree of agnosia for objects, and more especially for colours, and with marked failure in recognition of buildings, streets, and places. Visual memory exhibited a comparable defect in the reproduction of objects in their specific, though not in their generic, aspects. Intelligence and personality were well preserved.

An analysis of the disability together with a course of rehabilitation was attempted. It is concluded that 'agnosia for faces and places' reflects failure in recognition at its most highly specific and individual level.

\section{REFERENCES}

Bay, E. (1952). Dtsch. Z. Nervenheilk., 168, 1. (1953). Brain, 76, 515.

Bodamer, J. (1947). Arch. Psychiat. Nervenkr., 179, 6.

Bornstein, B., and Kidron, D. P. (1959). J. Neurol. Neurosurg. Psychiat., 22, 124.

Charcot, J. M. (1887). Leçons sur les Maladies du Système Nerveux. Delahaye and Lecrosme, Paris.

Chlenov, L. G., and Beyn, E. S. (1958). Zh. Nevropat. Psikiat., 58, 914 (In Russian).

Davidenkov, S. N. (1956). Clinical Lectures on Nervous Diseases, No. 2. Leningrad (In Russian).

Darkshevich, L. O. (1909). Course of Nervous Diseases, Vol. 2, No. 3 , p. 524. Kazan (In Russian).

Hécaen, H., and Ajuriaguerra, J. de (1956). Rev. neurol., 94, 222. Angelergues, R., Bernhardt, C., and Chiarelli, C. (1957). Ibid., 96, 125.

Hoff, H., and Pötzl, O. (1937). Z. ges. Neurol. Psychiat., 159, 367.

Lissauer, H. (1890). Arch. Psychiat. Nervenkr., 21, 222.

Pallis, C. A. (1955). J. Neurol. Neurosurg. Psychiat., 18, 218.

Poppelreuter, W. (1917). Die psychischen Schädigungen durch Kopfschuss im Kriege 1914-17, Vol. 1. Voss, Leipzig.

Wilbrand, H. (1892). Dtsch. Z. Nervenheilk., 2, 361. 